\title{
Short communication: Effect of different kefir grains on the attributes of kefir produced with milk from Costa Rica
}

\author{
Isabela de Sainz, ${ }^{1,2 *}$ ๑ Mauricio Redondo-Solano, ${ }^{3}$ Godofredo Solano, ${ }^{4}$ and Lautaro Ramírez ${ }^{1} \odot$ \\ ${ }^{1}$ Department of Chemical Engineering, University of Costa Rica, San Jose, Costa Rica 11501 \\ ${ }^{2}$ Institute of Engineering Investigation, University of Costa Rica, San Jose, Costa Rica 11501 \\ ${ }^{3}$ Tropical Disease Investigation Center and Section of Food Microbiology, Department of Microbiology and Immunology, Faculty of Microbiology, \\ University of Costa Rica, San Jose, Costa Rica 11501 \\ ${ }^{4}$ Nuclear Magnetic Resonance Unit, Natural Product Investigation Center, University of Costa Rica, San Jose, Costa Rica 11501
}

\section{ABSTRACT}

Kefir is an artisanal product that is gaining scientific attention due to its increase in consumption attributed to its potential health benefits. The effect on the quality attributes of kefir grains of different origin (household and commercial) and preserved with different methods (drying and freezing) was evaluated to standardize a domestic and semi-industrial process. Chemical (protein, lactose. lactic acid, ethanol, and acetic acid) as well as microbial properties (total plate count and total yeast count) were monitored during the experiment. Results show a statistical difference between the kefir grains in terms of acetic acid and ethanol percentages, which leads to the conclusion that there is a difference in the microbial populations that produce these products. Lactic acid, protein, and lactose parameters are statistically the same as well as the growth in biomass and the total population of yeast. Our results suggest that both types of kefir grains maintain a similar performance and that their metabolic capabilities are stable throughout time (taking into account that the household grains have been productive for years), meaning that domestic or semi-industrial processes could be easily standardized.

Key words: kefir grain, quality standard, fermentation, protein, lactose, lactic acid

\section{Short Communication}

The interest in studying and producing fermented milk beverages has increased in recent years due to the need for finding alternative methods for the prevention of chronic digestive diseases (Turkmen et al., 2019). Fermented dairy products are vehicles for probiotic bacteria, which help boost the immune system, aid

Received November 9, 2018.

Accepted August 10, 2019.

*Corresponding author: isabela.desainz@ucr.ac.cr the digestive system, and help protect the natural intestinal microbiota (Nale et al., 2017). Probiotics are defined as live microorganisms that, when administered in adequate amounts, confer a health benefit on the host (Hill et al., 2014).

Kefir is a product obtained from the fermentation of milk with mixed microflora found in the kefir grains: a complex mixture of bacteria and yeasts (Yilmaz-Ersan et al., 2018). The main products produced are lactic acid, ethanol, carbon dioxide, and aromatic compounds (Hatmal et al., 2018).

The chemical characteristics of milk kefir will depend on the composition of the kefir grains, the chemical components of the milk, and the technological process used to produce it (Gao and Li, 2016). Kefir contains partially digested proteins, so it is easier for the body to absorb them (Oliveira de Leite et al., 2013).

It is challenging to characterize kefir's complex matrix, not only at a nutritional level but also at a chemical and microbiological level (Gao and Li, 2016). It is essential to understand the factors affecting the production of kefir, including the source of grains. The Codex Alimentarius (FAO/WHO, 2011) describes quality standards for kefir, which was used to evaluate the quality of the product throughout the process.

In several studies, most of them carried out in the last decade, the primary interest is the characterization of the complex matrix of kefir microorganisms and their effect on the host (Oliveira de Leite et al., 2015; Prado et al., 2015; Arslan, 2016; Hatmal et al., 2018), the manufacture and characterization of kefir using only cow milk, different animal milks, or kefir grains and starter culture (Dinkci et al., 2015; Gul et al., 2015; Barukcic et al., 2017; Yilmaz-Ersan et al., 2018), the effect of different variables on the growth of kefir grains, and the modeling of its kinetic parameters (Pop et al., 2014; Apar et al., 2016). However, none of the studies were focused on the comparison of commercial and household kefir grains to determine if one or another is more beneficial for the product's final quality in terms of 
chemical and microbial characteristics. Kefir is a handcrafted product, with potential variability; despite this, quality is a crucial element for the value and stability of the product. Characterization of key microbiological parameters will support and ensure the quality and commercial production of handcrafted kefir.

Therefore, the objective of this study was to characterize the performance of kefir grains of different origin and preserved with different methods. Batch fermentations were performed to identify if there were differences between kefir produced with different grains; the quality parameters were used to control the product's properties. It is the first time the production of kefir has been documented using household kefir grains from Costa Rica.

The kefir grains used in this study came from 2 different sources; some grains were obtained locally from a Costa Rican household, and the others were acquired commercially through the American company Cultures for Health (Morrisville, NC); the latter are lyophilized kefir grains.

Since the commercial kefir grains are already lyophilized, we evaluated the effect of 2 preservation methods (freezing and drying) on the household kefir grains. For the freezing process, we weighed a $10 \mathrm{-g}$ sample of kefir grains and placed it in a glass container, covered the grains with milk ( $2 \%$ fat) from the Milk Producers Cooperative Dos Pinos R.L. (Alajuela, Costa Rica), pasteurized at UHT; then we placed it within a freezer at a temperature of $-8^{\circ} \mathrm{C}$ for $76 \mathrm{~h}$. The grains were defrosted at room temperature for $12 \mathrm{~h}$ and activated to carry out the fermentation experiments. For the dehydration method, we washed the grains with sterile distilled water, and 10-g samples were placed inside an oven at a temperature lower than $40^{\circ} \mathrm{C}$ (to avoid the inactivation of microbial populations) for around $76 \mathrm{~h}$ or until their mass remained constant; we determined this by weighing the sample several times until it did not decrease in mass. We stored the dehydrated samples inside airtight glass containers covered with powdered milk.

For activation, the preserved household grains, as well as the commercial lyophilized ones, were inoculated in UHT (2\% fat) treated milk inside a sterile container (5.5 g per $200 \mathrm{~mL}$ of milk) and kept in this environment for $24 \mathrm{~h}$ at room temperature. The grains were separated from the milk using filtration, using a filter with mesh size 14; then the same grains were used to reinoculate another batch of milk following the procedure described above, at the same ratio. We repeated this process 3 times; from this point on, the grains were considered activated. After activation, we maintained both types of grains at room temperature, in the same kind of milk used for experimentation. Fresh milk was fed daily, after discarding the old one, to keep the kefir grains' viability throughout the experimentation process.

In this study, 3 fermentations per type of activated grain (from domestic frozen, domestic dried, and commercial origin) were carried out in $24 \mathrm{~h}$ each, using milk treated at UHT ( $2 \backslash \%$ fat). The fermentations were performed using sterile $250-\mathrm{mL}$ Erlenmeyer flasks with a 3-cm mouth diameter and 7.5-cm bottom diameter. First, we heated the milk to the temperature at which the fermentation took place $\left(35^{\circ} \mathrm{C}\right)$, then the activated grains were added in quantities of $5.5 \mathrm{~g}$ per $200 \mathrm{~mL}$. The glass containers were placed on the grids of an orbital agitation incubation equipment (Shel Lab model SSI3, Sheldon Manufacturing Inc., Cornelius, OR), with controlled temperature $\left(35^{\circ} \mathrm{C}\right)$ and agitation $(50$ rpm) conditions. We did not choose the conditions of temperature, agitation, and kefir grain mass randomly; the experiments described in this article are the center points of a central composite statistical design that covers a wide range of conditions (not published).

The kefir grain mass determination is carried out after fermentation to monitor the percentage of biomass growth obtained from the grains. For this purpose, the grains were filtered using a plastic strainer with mesh size no. 14 that was previously sanitized with $70 \%$ alcohol and evaporated inside a laminar flow microbiological safety cabinet (BSC, Labculture class II, type A2, E-series; Esco Micro Pte. Ltd., Singapore). The kefir grains were rinsed inside this filter with distilled water. Then, the grains were left to dry at room temperature on filter paper. Finally, we weighed the kefir grains on a precision balance (Radwag model PS 2100 R1, Radwag USA LLC, Miami, FL), and the initial weight was subtracted to indicate the growth of biomass.

Chemical analysis of kefir includes the determination of protein, lactose, total acidity, acetic acid, and ethanol. Protein content after fermentation was determined using the Kjeldahl method (ISO, 2014).

The Fehling method (Lane and Eynon method) was used to determine lactose, reducing the sugar due to the presence of a free hemiacetal hydroxyl group (NFSS, 2010).

We determined total acidity through the titratable acidity measurement method (ISO, 1980).

Determinations of ethanol and acetic acid concentration in kefir using proton nuclear magnetic resonance (1H-NMR) procedures and conditions were adapted from reported methods for dairy products (Sundekilde et al., 2014; Antunes-Fernandes et al., 2016; Lu et al., 2018).

We quantified lactic acid bacteria and yeast from the kefir grains on de Man, Rogosa, and Sharpe (MRS) agar and potato dextrose agar (PDA) agar with chlor- 
amphenicol, respectively. Ten-fold dilutions in $0.1 \%$ sterile peptone water were plated on both MRS and PDA plates. We incubated MRS plates for 24 to 36 $\mathrm{h}$ in anaerobic conditions (containers where oxygen was depleted by burning a candle to create a low $\mathrm{O}_{2}$ and high $\mathrm{CO}_{2}$ environment), and PDA plates for a minimum $48 \mathrm{~h}$ under aerobic conditions, both at room temperature (approximately $23^{\circ} \mathrm{C}$ ). We indicated the microbial survival rate by counts made before and after each preservation treatment (freezing and drying), and the microbial growth rate by counts made before and after fermentation. The genus and species were not determined because the interest was predominantly in knowing how the total count affects the chemical quality and not which type of bacteria or yeast survive.

We analyzed the data with a hypothesis for 2 medians and comparison for 2 treatments to evaluate if there was a significant difference between the kefir grains used, with each type of kefir grains as a treatment. For $\alpha=0.05, \mathrm{nx}+$ ny $-2 \mathrm{df}$ and a null hypothesis of the form $\mathrm{H}_{0}: \mu \mathrm{x}=\mu \mathrm{y}$.

As mentioned before, preservation treatments were only carried out on household unpreserved kefir grains. The objective was to obtain a method suitable for grain preservation and maintenance throughout the study, as well as throughout kefir domestic and semi-industrial production. However, before applying any preservation method, microbiological counts of both yeasts and lactic acid bacteria were performed on both types of starter cultures (domestic and commercial) after the activation of the grains. In Table 1, we can see the results obtained before preservation treatments for both types of grains. Lactic acid bacteria and yeast counts did not differ between local grains and purchased grains $(P>0.05)$, not rejecting the hypothesis and concluding that the values are not significantly different.

The local kefir grains were subjected to both freezing and dehydration processes to evaluate the survival of bacteria and yeast, in terms of the total counts. Table 1 shows the bacterial and yeast counts before and after each treatment.

According to the literature, during freezing and activation of kefir grains, temperature conditions and the concentration of grains are some of the variables that can affect the percentage of microbial survival within the sample (Chen et al., 2006). For this part of the experiment, the same activation conditions were analyzed, at room temperature, without agitation and following the procedure explained above. We used milk as a means of preservation (in the case of freezing) and activation, and the concentration during activation of grains was $5.5 \mathrm{~g}$ per $200 \mathrm{~mL}$ per sample.

The $P$-values obtained for lactic acid bacteria and yeast counts after freezing were 0.85 and $0.35(>0.05)$ respectively, not rejecting the hypothesis and indicating that the data are not significantly different. For the dehydration method, the $P$-values for lactic acid bacteria and yeast were $0.01(<0.05)$ and $0.73(>0.05)$, concluding that the drying method is not suitable for the preservation of bacteria because there is a significant difference between the bacterial counts before and after this preservation method. We attribute this to poor rehydration conditions; at a rehydration temperature of $25^{\circ} \mathrm{C}$ the recovery of yeast is greater than that of bacteria in kefir grains due to the damage to the cell during drying (Chen et al., 2006). On the other hand, although the dehydration temperature does not exceed $40^{\circ} \mathrm{C}$, subjecting grains to these temperatures for long periods can cause damage to the cell and thus affect the recovery of microorganisms when reactivating the grains.

Bacteria had a higher survival rate after freezing compared with yeasts. This could have been because the recovery of bacteria cells when milk is used as a means of preservation in freezing is more significant, because milk has specific characteristics that make it an efficient cryoprotectant (the substance that is used to protect the cell against freezing damage; Kaewiad et al., 2016). Other reports in the literature have also indicated that lactic acid bacteria survive the freezing process better than fungi and yeasts; although the latter can survive freezing, the survival rate is much lower than that observed for bacteria (Bolla et al., 2011). Additionally, some literature reports show that the freezing rate (the speed at which the temperature drops) has a greater effect on the viability of fungi and yeasts than on that of lactic acid bacteria (Ojha and Brijesh, 2016).

The results in Table 2 show no significant differences ( $\alpha=0.05)$ in terms of mass growth for the fermentation experiments carried out with the 2 types of kefir grains. We evaluated biomass growth as a percentage increment in biomass; we showed that the household grains (preserved by freezing) had a biomass increase of $7.20 \pm 0.13 \%$, whereas the lyophilized commercial grains had a biomass increase of $7.18 \pm 0.19 \%$. We concluded that under the operating conditions at which the

Table 1. Microbial counts (means \pm SD) before preservation treatment for both types of grains and after treatments for local grains only

\begin{tabular}{lcc}
\hline Item & Yeast & Bacteria \\
\hline Local grains, log $(\mathrm{cfu} / \mathrm{mL})$ & $7.92 \pm 0.06$ & $8.21 \pm 0.14$ \\
Purchased grains, log $(\mathrm{cfu} / \mathrm{mL})$ & $7.91 \pm 0.04$ & $8.23 \pm 0.20$ \\
After freezing, $\log (\mathrm{cfu} / \mathrm{mL})$ & $7.87 \pm 0.06$ & $8.18 \pm 0.13$ \\
After dehydration, $\log (\mathrm{cfu} / \mathrm{mL})$ & $7.90 \pm 0.05$ & $7.82 \pm 0.05^{*}$ \\
\hline
\end{tabular}

*Significantly different $(\alpha=0.05)$. 
Table 2. Comparison of experimental and theoretical quality parameters (means $\pm \mathrm{SD}$ ) of kefir

\begin{tabular}{|c|c|c|c|c|}
\hline Parameter & Local grains (frozen) & Purchased grains & $\begin{array}{l}\text { Codex } \\
\text { Alimentarius }^{1}\end{array}$ & $P$-value \\
\hline Yeasts, $\log (\mathrm{cfu} / \mathrm{mL})$ & $6.61 \pm 0.06$ & $6.63 \pm 0.05$ & $\min 4$ & 0.71 \\
\hline Bacteria and yeasts, $\log (\mathrm{cfu} / \mathrm{mL})$ & $13.55 \pm 0.04$ & $13.58 \pm 0.06$ & $\min 7$ & 0.61 \\
\hline Protein (\%) & $4.36 \pm 0.06$ & $4.35 \pm 0.02$ & $\min 2.7$ & 0.64 \\
\hline Lactose (\%) & $2.94 \pm 0.11$ & $2.92 \pm 0.07$ & - & 0.76 \\
\hline Total acidity (\%) & $1.22 \pm 0.03$ & $1.23 \pm 0.01$ & $\min 0.6$ (lactic acid) & 0.73 \\
\hline
\end{tabular}

${ }^{1} \min =$ minimum. Codex Alimentarius: FAO/WHO, 2011.

fermentations are carried out, both types of kefir grains react in the same way in terms of physical growth.

We determined chemical and microbiological characteristics (percentage of proteins, lactose, ethanol, lactic and acetic acid, and total bacteria and yeast counts) of kefir at the end of the fermentation processes. We compared the results (reported as averages) with the quality parameters indicated by the Codex Alimentarius. Table 2 shows no significant differences $(P>0.05)$ for any of the data. The lactic acid percentage can be determined by subtracting the acetic acid percentage from the total acidity percentage, in the supposition that these 2 acids are the only 2 produced during fermentation. Results show that the lactic acid percentage is $1,134 \pm 0.033$ for local frozen grains and 1,153 \pm 0.017 for lyophilized purchased grains, complying with the Codex Alimentarius standard for lactic acid percentage.

Although the Codex Alimentarius does not propose a quality limit for the percentage of lactose, the lactose level depends on the matrix composition and whether it was fortified (Gao and Li, 2016). The product analyzed has lower percentages of lactose than those reported in the literature, a consequence of a higher microbial growth, which promotes the consumption of lactose, and therefore, the generation of organic acids. The lower lactose content and higher microbial counts make the product suitable for people with lactose intolerance.

This study is the first evaluating the quality parameters of kefir by comparing the performance of kefir grains of household and commercial origin. The results from this study give technical insight for the standardization of domestic or semi-industrial production of kefir fermentation. We observed no differences in terms of biomass growth and total microbial replication; we conclude that both kefir grains are suitable to obtain a product that meets the quality parameters for kefir presented by the Codex Alimentarius. The last is an advantage in terms of the possibility of process standardization for kefir at both the domestic and semiindustrial levels. Total counts of microbial populations do not affect the quality parameters stated by the Codex Alimentarius, even though they are from different sources of grains.

Regarding the preservation method, we conclude that freezing is a suitable option as this method can preserve the bacteria within the kefir grains better than the drying method. It has to be clarified that before and after the preservation methods, the counts were made to obtain the total of colony-forming units per milliliter, because the interest is to know how the total populations affect the chemical quality parameters, not to know which specific bacteria and yeast survived.

As kefir could be considered a living product that needs ideal conditions to grow, experiments must be carried out at different values of temperature, agitation, and kefir-to-milk ratio to choose the optimum process conditions employing a 3-dimensional statistical analysis (central composite design).

The fermented dairy market in Costa Rica is growing, with yogurt consumption showing a $10 \%$ increase between 2015 and 2016 (La Nación, 2017). More than 212 fermented milk products are available in the Costa Rican market. Further research is needed to support this growing food category. For example, process-focused studies looking to optimize production parameters, such as temperature, agitation, and kefir-to-milk ratio, are necessary to improve quality. Consumer-facing sensory studies using projective mapping, quantitative descriptive analysis, and temporal dominance of sensation would also be useful in building sensory-based systems to support product quality and continued fermented milk product growth (Karaçali et al., 2018).

\section{ACKNOWLEDGMENTS}

The research was funded by the University of Costa Rica, a public university. Special thanks to the Department of Chemical Engineering, the Tropical Disease Investigation Center (CIET), and the Natural Product Investigation Center (CIPRONA). 


\section{REFERENCES}

Antunes-Fernandes, E. C., S. Van Gastelen, J. Dijkstra, K. A. Hettinga, and J. Vervoort. 2016. Milk metabolome relates enteric methane emission to milk synthesis and energy metabolism pathways. J. Dairy Sci. 99:6251-6262. https://doi.org/10.3168/jds.2015-10248.

Apar, D., E. Demirhan, B. Ozel, and B. Ozbek. 2016. Kefir grains biomass production: Influence of different culturing conditions and examination of growth kinetic models. J. Food Process Eng. 40:312332. https://doi.org/10.1111/jfpe.12332.

Arslan, S. 2016. A review: Chemical, microbiological and nutritional characteristics of kefir. CYTA J. Food 13:340-345. https://doi .org/10.1080/19476337.2014.981588.

Barukcic, I., L. Gracin, A. Jambrak, and R. Bozanic. 2017. Comparison of chemical, rheological and sensory properties of kefir produced by kefir grains and commercial kefir starter. Mljekarstvo 67:169-176. https://doi.org/10.15567/mljekarstvo.2017.0301.

Bolla, P. A., M. de los Angeles Serradell, P. J. de Urraza, and G. L. D. Antoni. 2011. Effect of freeze drying on viability and in vitro probiotic properties of a mixture of lactic acid bacteria and yeasts isolated from kefir. J. Dairy Res. 78:15-22. https://doi.org/ 10.1017/S0022029910000610.

Chen, H.-C., C. W. Lin, and M. J. Chen. 2006. The effects of freeze drying and rehydration on survival of microorganisms in kefir. J. Anim. Sci. 19:126-130. https://doi.org/10.5713/ajas.2006.126.

Dinkci, N., H. Kesenkas, F. Korel, and O. Kinik. 2015. An innovative approach: Cow/oat milk-based kefir. Mljekarstvo 65:177-186. https://doi.org/10.15567/mljekarstvo.2015.0304.

FAO/WHO. 2011. Codex Alimentarius: Milk and milk products. 2nd ed. World Health Organization, Geneva, Switzerland; Food and Agriculture Organization, Rome, Italy.

Gao, X., and B. Li. 2016. Chemical and microbiological characteristics of kefir grains and their fermented dairy products: A review. Cogent Food Agric. https://doi.org/10.1080/23311932.2016.1272152.

Gul, O., M. Mortas, M. Dervisoglu, and T. Kahyaoglu. 2015. Manufacture and characterization of kefir made from cow and buffalo milk, using kefir grain and starter culture. J. Dairy Sci. 98:1517-1525. https://doi.org/10.3168/jds.2014-8755.

Hatmal, M. M., A. Nuirat, M. Zihlif, and M. Taha. 2018. Exploring the influence of culture conditions on kefir's anticancer properties. J. Dairy Sci. 101:3771-3777. https://doi.org/10.3168/jds.2017-13539.

Hill, C., F. Guarner, G. Reid, G. Gibson, D. Merenstein, B. Pot, L. Morelli, R. Canani, H. Flint, S. Salminen, P. Calder, and M. Sanders. 2014. The International Scientific Association for Probiotics and Prebiotics consensus statement on the scope and appropriate use of the term probiotic. Nat. Rev. Gastroenterol. Hepatol. 11:506-514. https://doi.org/10.1038/nrgastro.2014.66.

ISO. 1980. Dried milk-determination of titratable acidity (routine method). ISO 6092:1980. International Organization for Standardization (ISO), Geneva, Switzerland.

ISO. 2014. Milk and milk products-Determination of nitrogen content- Part 1: Kjeldahl principle and crude protein calculation. ISO 8968-1:2014. International Organization for Standardization (ISO), Geneva, Switzerland.

Kaewiad, K., N. Kaewnopparat, D. Faroongsarng, J. Wungsintaweekul, and S. Kaewnopparat. 2016. Optimisation of Bambara groundnut water extract and skim milk composition as cryoprotectant for increasing cell viability of Lactobacillus spp. using response surface methodology. Int. J. Food Sci. Technol. https://doi.org/10.1111/ ijfs.13249.

Karaçali, R., N. Özdemir, and A. H. Çon. 2018. Aromatic and functional aspects of kefir produced using soya milk and Bifidobacte- rium species. Int. J. Dairy Technol. 71:921-933. https://doi.org/ 10.1111/1471-0307.12537.

La Nación. 2017. Yogurt es el lácteo con más crecimiento de demanda en país. Accessed Mar. 14, 2018. https://www.nacion.com/economia/ consumo/yogurt-es-el-lacteo-con-mas-crecimiento-de-demanda-en -pais/IARE2MHFLNGBVNF45MUBAC4C6Y/story/.

Lu, Y., H. Ishikawa, Y. Kwon, F. Hu, T. Miyakawa, and M. Tanokura. 2018. Real-time monitoring of chemical changes in three kinds of fermented milk products during fermentation using quantitative difference nuclear magnetic resonance spectroscopy. J. Agric. Food Chem. 66:1479-1487. https://doi.org/10.1021/acs.jafc.7b05279.

Nale, Z., I. Tontul, A. Arslan, H. Sahin, and A. Kucukcetin. 2017. Microbial viability, physicochemical and sensory properties of kefir microcapsules prepared using maltodextrin/Arabic gum mixes. Int. J. Dairy Technol. 71:61-72. https://doi.org/10.1111/1471 $-0307.12402$

NFSS. 2010. Determination of lactose and sucrose in foods for infants and young children, milk and milk products. National Food Safety Standard GB 5413.5-2010. Ministry of Health of the People's Republic of China, Beijing, China.

Ojha, K. S., and K. T. Brijesh. 2016. Novel Food Fermentation Technologies. Springer International Publishing, New York, NY.

Oliveira de Leite, A., M. A. L. Miguel, R. S. Peixoto, A. S. Rosado, J. T. Silva, and V. M. F. Paschoalin. 2013. Microbiological, technological and therapeutic properties of kefir: A natural probiotic beverage. Braz. J. Microbiol. 44:341-349. https://doi.org/10.1590/ S1517-83822013000200001.

Oliveira de Leite, A., M. A. L. Miguel, R. S. Peixoto, P. Ruas-Madeido, V. M. F. Paschoalin, B. Mayo, and S. Delgado. 2015. Probiotic potential of selected lactic acid bacteria strains isolated form Brazilian kefir grains. J. Dairy Sci. 98:3622-3632. https://doi.org/10 $.3168 /$ jds.2014-9265.

Pop, C., S. Apostu, L. Salanta, A. Rotar, M. Sindic, N. Mabon, and C. Socaciu. 2014. Influence of different growth conditions on the kefir grains production used in the kefiran synthesis. Bull. UASVM Food Sci. Technol. 71:147-153. https://doi.org/10.15835/ buasvmcn-fst:10802.

Prado, M. R., L. M. Blandón, L. P. S. Vandenberghe, C. Rodrigues, G. R. Castro, V. T. Soccol, and C. R. Soccol. 2015. Milk kefir: Composition, microbial cultures, biological activities, and related products. Front. Microbiol. 6:1177. https://doi.org/10.3389/fmicb .2015.01177.

Sundekilde, U. K., F. Gustavsson, N. A. Poulsen, M. Glantz, M. Paulsson, L. B. Larsen, and H. C. Bertram. 2014. Association between the bovine milk metabolome and rennet-induced coagulation properties of milk. J. Dairy Sci. 97:6076-6084. https://doi.org/10 .3168/jds.2014-8304.

Turkmen, N., C. Akal, and O. Barbaros. 2019. Probiotic diary-based beverages: A review. J. Funct. Foods 53:62-75. https://doi.org/10 .1016/j.jff.2018.12.004.

Yilmaz-Ersan, L., T. Ozcan, A. Akpinar-Bayizit, and S. Sahin. 2018. Comparison of antioxidant capacity of cow and ewe milk kefirs. J. Dairy Sci. 101:3788-3798. https://doi.org/10.3168/jds.2017-13871.

\section{ORCIDS}

Isabela de Sainz ํㅜ https://orcid.org/0000-0003-4627-523X Lautaro Ramírez @ https://orcid.org/0000-0002-4564-2125 